EMBRYARIDDLE
Aeronautical University

SCHOLARLY COMMONS
International Journal of Aviation, Aeronautics, and Aerospace

\title{
Ultrafine aluminium: Quench collection of agglomerates
}

TEJASVI K

DEFENCE RESEARCH AND DEVELOPMENT ORGANISATION, tejasvichem@gmail.com

Y PYDI SETTY

ypydisetty@yahoo.com

VEMANA VENKATESWARA RAO

VEMANAVRAO@GMAIL.COM

Follow this and additional works at: https://commons.erau.edu/ijaaa

Part of the Propulsion and Power Commons

\section{Scholarly Commons Citation}

K, T., SETTY, Y., \& VENKATESWARA RAO, V. (2019). Ultrafine aluminium: Quench collection of agglomerates. International Journal of Aviation, Aeronautics, and Aerospace, 6(1). https://doi.org/ 10.15394/ijaaa.2019.1324

This Article is brought to you for free and open access by the Journals at Scholarly Commons. It has been accepted for inclusion in International Journal of Aviation, Aeronautics, and Aerospace by an authorized administrator of Scholarly Commons. For more information, please contact commons@erau.edu. 


\section{Introduction}

The feature of ultrafine aluminium is expected to be different from the micro-sized aluminium particles, because of some traits of ultrafine aluminium improvement in the propellant performance. The desirable attributes of ultrafine aluminium particles are its high surface area, low melting, ignition temperature, agglomerates of smaller size, and reduction in smoke from exhaust signature point of view. The inclusion of ultrafine aluminium particles in propellants is to increase the energetic of the propellant. Recently, several researchers have been carried out on the production of ultra-fine particles using different techniques and their effects on solid propellant combustion (Dokhan, 2002; Galfetti et al. 2006; Jayaraman, Anand, Bhatt, Chakravarthy, \& Sarathi, 2009). Several techniques are reported for producing ultra-fine aluminum such as vaporization/condensation, called the Gen-Miller method (Gen \& Miller, 1981; Gen, Ziskin, \& Petrov, 1959; Jigatch, Leipunsky, Kuskov, Stoenko, \& Storozhev, 2002), plasma recondensation (Mazalov, Bogdanova, Ivashkevich, Pavlovets, \& Chinnov, 1993; Salko, 1995), mechanical milling (Khan, Farrokh, \& Takacs, 2008), chemical synthesis (Khan, Farrokh, \& Takacs, 2008), inert gas condensation (Gutmanas, Trusov, \& Gotman, 1994; Sanchez-Lopez, Caballero, \& Fernandez, 1998), $\mathrm{H}_{2}$ plasma evaporation (Sun, Cong, Sun, \& Yang, 1999), electro explosion of wire (Argonide, n.d.; Gash, 2005; Sedoi, \& Valevich, 1999), and the combustion behavior of various propellant compositions containing ultra-fine aluminium (Simonenko, \& Zarko, 1999). Recently, Sai Karthick et al. (2018) reported Ultrafine Al powder synthesis using Radio Frequency Induction Plasma technique. The process essentially encompasses induction heating followed by inert gas condensation to yield ultrafine particles. However, the heating process of injected metal precursors in RFIP is significantly dependent on various operational parameters, such as plasma power, and precursor feed rate and size; the produced particles are in the range of 167-508 nm sizes. Galfetti et al. (2016) reported the average size of condensed combustion products at $0.1 \mathrm{MPa}$ to be $6.6 \mu \mathrm{m}$ from a propellant containing 150 $\mathrm{nm}$ sized aluminium, as opposed to $13 \mu \mathrm{m}$ with that containing $300 \mathrm{~nm}$ sized aluminium, which confirm the substantial agglomeration of the former. Dokhan (2002) reported size measurement of non-smoke combustion residue (NSCR) in propellants that contain bimodal blends of ultra-fine with the size less than $10 \mu \mathrm{m}$. Although this is of practical significance, it is difficult to distinguish the extent of agglomeration of ultra-fine aluminium from that of micrometer sized aluminium. Povinelli and Rosenstein (1964) reported the size distribution of alumina with the size ranges from $4 \mu \mathrm{m}$ to $60 \mu \mathrm{m}$ from composite propellant combustion. Sambamurthi (1996) measured the size of alumina particles with the size ranges from $8 \mu \mathrm{m}$ to $11 \mu \mathrm{m}$ in the plume of large rocket motors. Glotov (2006) has reported that agglomeration of aluminium in nitramine-containing propellants, and has shown that the agglomerate size did not correlate with either increase in 
burning rate or with increase in pressure. However, in general, it is pointed out that the agglomerate size varies inversely with the propellant burning rate (Price, Sambamurthi, Sigman, \& Panyam, 1986). The LEF (Leading Edge Flame) distribution analysis is adopted to examine the heat transfer to Al agglomerates and ignition delay of accumulated aluminium filigrees on the burning surface to estimate the agglomerate size distribution (Srinivas \& Chakravarthy, 2007).

Post-burning analysis of solid propellants containing nano-particles and micro-particles shows that the nano-aluminized propellant has higher combustion efficiency than a micron-aluminized propellant; also, the pressure effect on the chemical composition, size, and morphology of the combustion residues is significant (Galfetti et al. 2007). Recently, authors reported aluminium agglomerate size distribution of around 1-5 $\mu \mathrm{m}$ from propellants (Jayaraman, Chakravarthy, \& Sarathi, 2011) and sandwiches (Jayaraman, Chakravarthy, \& Sarathi, 2010) using experiments which contains nano-aluminium particles with the size of $50 \mathrm{~nm}$ produced from electrical wire explosion and also the micron-sized aluminium particles agglomeration in propellants using both experimental and modelling studies (Anand, 2013). These studies are carried out by maintaining the distance between burning surface and quench distance as constant. Hence, most of the studies reported the agglomerated aluminium or its combusted alumina particles whereas the studies on the effect of quenching/collecting distance from the burning surface and accordingly the influence of pressure is very limited, particularly with ultra-fine aluminium particles. The authors of this research investigated ultra-fine aluminium agglomerate size distribution from the propellant burning using Quench collection over a wide range of variation in quench distances and pressure ranges when compared to past works. The agglomerate quenching distance variation from propellant burning using ultra-fine aluminium particles reported in this study can be considered as a major step forward for estimating the aluminium agglomerate fragmentation, smoke signatures, and two-phase flow losses to thrust. The experiments were carried out for pressure between ranges $2 \mathrm{MPa}$ to $8 \mathrm{MPa}$ and six quench distances from the propellant burning surface using ultra-fine added propellants. The quenched particles are chemically analyzed for estimating the elemental compositions and determined the particle size distribution.

\section{Experimental Details}

\section{Ingredients and samples}

The ingredients used in this study were Ultra-fine aluminium, Hydroxylterminated poly-butadiene (HTPB) as a binder, and Ammonium Perchlorate (AP) as an oxidizer. The coarse AP particles are subjected to size reduction in the fluid energy mill to reduce the size and sieved between meshes to obtain fine particles. 
A bicurative system based on TDI and IPDI was selected to include $18 \%$ ultrafine aluminium in the propellant compositions by keeping the ratio of TDI/IPDI for better curing; keeping the R-value at 0.97 with processing temperature of 44 ${ }^{\circ} \mathrm{C}$, as mentioned in Table 1 . The propellant ingredients are weighed and manually mixed thoroughly, followed by transferring the mixture into a micromixer. The mixture is then transferred into a vacuum-cast container, where a plunger is used to remove the blowholes during evacuation. The end of mix viscosity and viscosity buildup of the propellant slurry was determined using a Brookfield viscometer by inserting a $\mathrm{T}$ - $\mathrm{C}$ spindle with the rotating speed of 2.5 $\mathrm{rpm}$ at a predetermined temperature. Then, the sample is placed in hot air oven at $50^{\circ} \mathrm{C}$ for about 7 days for curing. The burning rate of cured propellant samples was determined using an acoustic emission technique in an inert nitrogen atmosphere. The cured samples are cut into cylindrical discs with $25 \mathrm{~mm}$ diameter and $5 \mathrm{~mm}$ thickness.

Table 1.

Ultra-fine Aluminium Powder Propellant Formulations

\begin{tabular}{|l|l|}
\hline Ingredients, \% & Compositions \\
\hline $\begin{array}{l}\text { Binder + Curator }+ \\
\text { additives }\end{array}$ & 14 \\
\hline Oxidizer(bimodal) & 68 \\
\hline Ultra-fine Al Powder & 18 \\
\hline TDI/IPDI & $32 / 68$ \\
\hline
\end{tabular}

\section{Quench Collection Set-Up and Al Agglomerate Collection}

The quench collection setup consists of a stainless-steel pressure vessel which is designed to withstand a maximum working pressure of $20 \mathrm{MPa}$, and also propellant holder with ignition rods. The schematic of the configuration is shown in Figure 1. The collecting vessel is designed for collecting the agglomerates in the ethanol bath and placed at a distance of $5 \mathrm{~mm}, 23 \mathrm{~mm}, 35 \mathrm{~mm}, 47 \mathrm{~mm}, 59 \mathrm{~mm}$, and $71 \mathrm{~mm}$ below the propellant burning surface. For each set of experiments, quenching was performed for four different pressures to collect the aluminium agglomerates. The propellant is mounted below the propellant holder and nichrome wire is wound to the electrodes to initiate the ignition. The bomb is closed after fixing the propellant sample and pressurized using the nitrogen gas. The test conditions of different pressures and quench distances are mentioned in Table 2. Once the propellant gets ignited and the aluminium agglomerates emerging out from the propellant burning surface is quenched in the ethanol bath. 
The quenched agglomerates are allowed to settle and the ethanol is allowed to evaporate. The dried agglomerates are viewed and captured the image using the microscope and several images are obtained for processing to determine the size distribution.

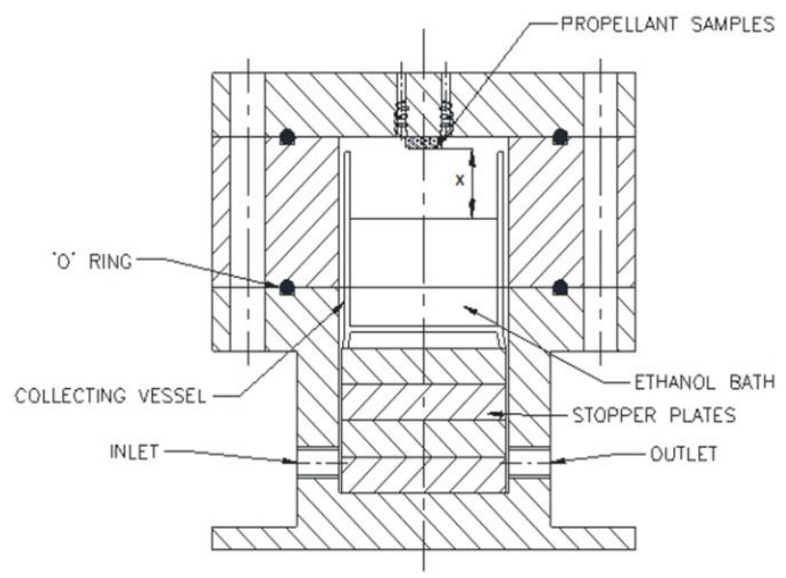

Figure 1. Quench Collection Set up.

Table 2.

Test conditions for study of Quench Distances versus Pressure study

\begin{tabular}{|c|c|c|}
\hline $\begin{array}{c}\text { Propellant } \\
\text { Identification }\end{array}$ & $\begin{array}{c}\text { Operating } \\
\text { Pressure } \\
(\mathrm{MPa})\end{array}$ & $\begin{array}{c}\text { Quench Distance } \\
\text { from propellant } \\
\text { burning surface, } \\
\text { x (mm) }\end{array}$ \\
\hline \multirow{2}{*}{$\begin{array}{c}\text { Ultra-fine } \\
\text { aluminized } \\
\text { propellant } \\
\text { composition }\end{array}$} & 2 & \multirow{2}{*}{$5,23,35,47,59,71$} \\
\cline { 2 - 2 } & 8 & \\
\hline
\end{tabular}

\section{Al Agglomerate Size Determination}

In general, the condensed phase combustion particles have wide range of sizes, since these are emerging as condensed substances from the propellant surface layer; mostly the aluminium agglomerate sizes are more than the initial aluminium particle size. The aluminium metal is opaque and does not let the light to pass through it; whereas the alumina portion of the quenched particle is 
translucent and can easily be distinguished from the aluminium portion. From the images, aluminium content alone is considered as agglomerates and is further used for the size analysis. The particles are digitally identified, and their edges are detected using computer software. The pixels contained within the detected edges are used to find an equivalent diameter of a circular projection of each particle, to obtain its size for a given magnification using the pixel distances. These images were processed using ImageJ (a particle and image analysis tool) software, which provides the size information of all the agglomerates, the sizes were calculated and determined from each image. A total number of at least 1000 agglomerates were counted to get the size distribution for each test. About $90 \%$ of the cases are repeated at least once to ensure that the repeatability is within $5 \%$ of the agglomerate size distributions obtained in different cases. The agglomerate size is recognized as it is greater than the parent aluminium size in the distribution. The Sauter mean diameter (SMD), which is representative of the ratio of volume to the surface area, is considered to represent the nominal size of the agglomerates. Similarly, the arithmetic mean diameter (AMD) of the agglomerates is also presented in the nominal size plots. The Sauter mean diameter (SMD) and the arithmetic mean diameter (AMD) of the agglomerates are determined based on the following definitions:

$$
\begin{gathered}
D_{32}=\sum\left(n_{i} d_{i}^{3}\right) /\left(n_{i} d_{i}^{2}\right) \\
D_{10}=\sum\left(n_{i} d_{i}\right) /\left(n_{i}\right)
\end{gathered}
$$

Where $n_{i}$ refers to number of particles with diameter $d_{i}$ and $d_{i}$ is nominal diameter of $i^{\text {th }}$ particle.

\section{Results and Discussions}

\section{Viscosity Build-Up and Burn Rate Measurement of Propellants}

The end of propellant mix temperature was $44^{\circ} \mathrm{C}$ and corresponding viscosity was 10,400 Poise. The viscosity buildup revealed that the pot life of the slurry using bicurative system based on $18 \%$ ultra-fine aluminium was more than $2 \frac{1}{2} \mathrm{hrs}$. The burning rate was determined using an acoustic emission technique. The measured burn rate was $15.25 \mathrm{~mm} / \mathrm{sec}$ at 50 bar agreed well as earlier reported by authors for nano-aluminized propellants (Jayaraman et al., 2009a/b). Increase in burning rate may be attributed to large surface area and near surface ignition of the ultra-fine aluminum particles as reported (Galfetti et al., 2006/2007). 


\section{The Condensed Combustion Products Analysis}

Combustion of metallized solid rocket propellants in the formation of condensed combustion products (CCP), which have an essential influence on rocket motor performance. Different techniques are proposed in the literature to collect and analyze the condensed combustion products. Agglomerates are systems made of aluminium and aluminium oxide, formed during the combustion process, whose size is significantly over the initial Al size. Two mechanisms can be adopted to explain this phenomenon. First, the agglomerates may be not completely transformed to molten droplets before they get quenched, which makes the particles are spherical in shape and these incompletely molten particles are termed as aggregates, which are composed of partially molten aluminium particles. Another possibility is relevant to the ignition nature of aluminium droplets. As the aluminium accumulation acts as a heat sink, ignition is provided directly by the premixed flame at lower pressure, but the attachment of LEFs to AP particles causes the ignition sources to be localized at intermediate pressures. At elevated pressures, the LEFs approach closer to the burning surface and effectively ignite the accumulated aluminium, thus reducing the agglomerate size. Figure $2 \& 3$ shows the SEM micrograph of aluminium agglomerates, in which the flame is quenched and residues collected from the vessel at $2 \mathrm{MPa}$ and $8 \mathrm{MPa}$ along with ESD analysis results. The aluminium particles are mostly opaque, so they appear black in color. Significant agglomeration is observed, as cluster sizes are much larger than the parent aluminium particles; the maximum agglomerate size does not exceed $21 \mu \mathrm{m}$. Highlights in the figures are the large clusters of aluminium agglomerates that are in the range of $11-21$ micrometer size range. Other parameters were deduced and computed from results obtained for each pressure, the size distribution and cumulative frequency of agglomerates are shown in Figure 4. Figure 5 demonstrates the agglomerate size decreases with increasing pressure and quenches distances, which is almost monotonic. Besides, the quenching distance are also influence $\mathrm{Al}$ agglomeration feature, as the distance between the burning surface and quenching is increased, the Al agglomerates start to ignite and subsequent burning leads to fragmentation of agglomerates, provides heat feedback to the upcoming agglomerates, by considering the competent and all together factors be in the lead to agglomerate size reduction mechanism. 
K et al.: UFAL: QUENCH COLLECTION OF AGGL.
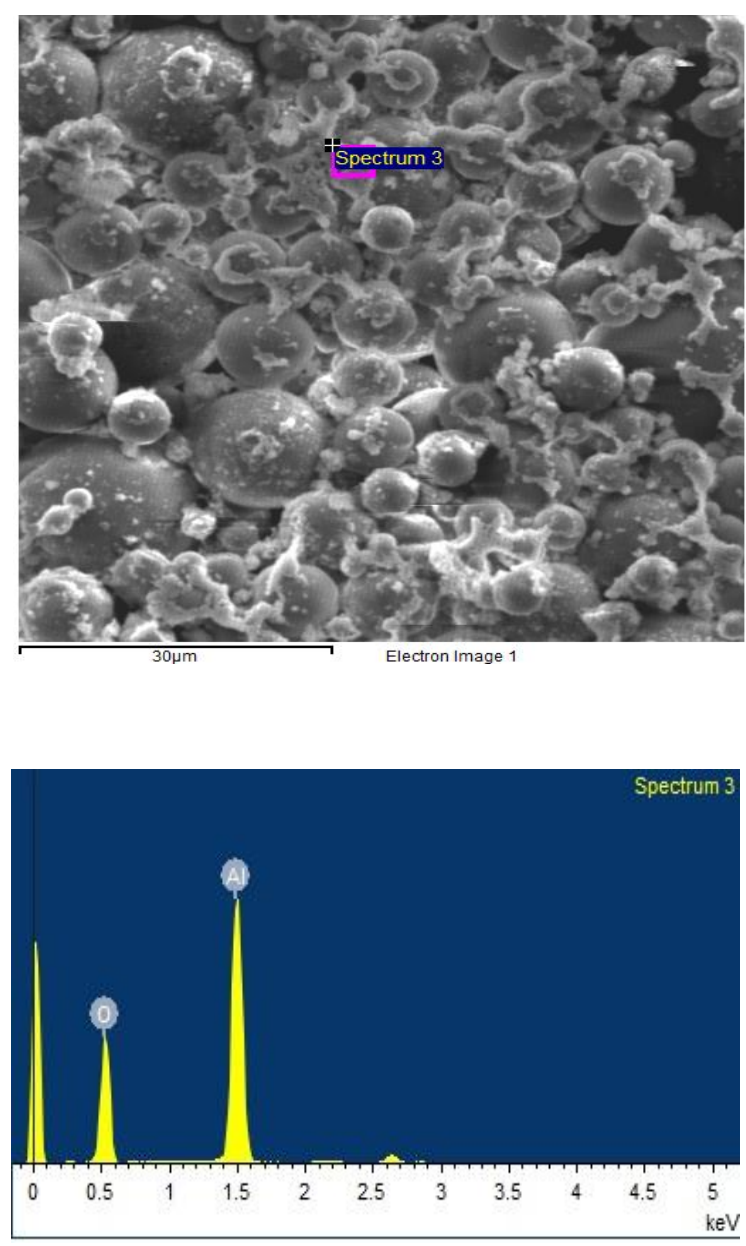

\begin{tabular}{|c|c|c|}
\hline Element & Weight $\%$ & $\begin{array}{c}\text { Atomic } \\
\%\end{array}$ \\
\hline O K & 53.92 & 66.37 \\
\hline Al K & 46.08 & 33.63 \\
\hline Total & 100.00 & \\
\hline
\end{tabular}

Figure 2. SEM Image and EDS Chemical Spectrum of Ultra-fine Aluminium Sample Quench Collected at 2MPa. 


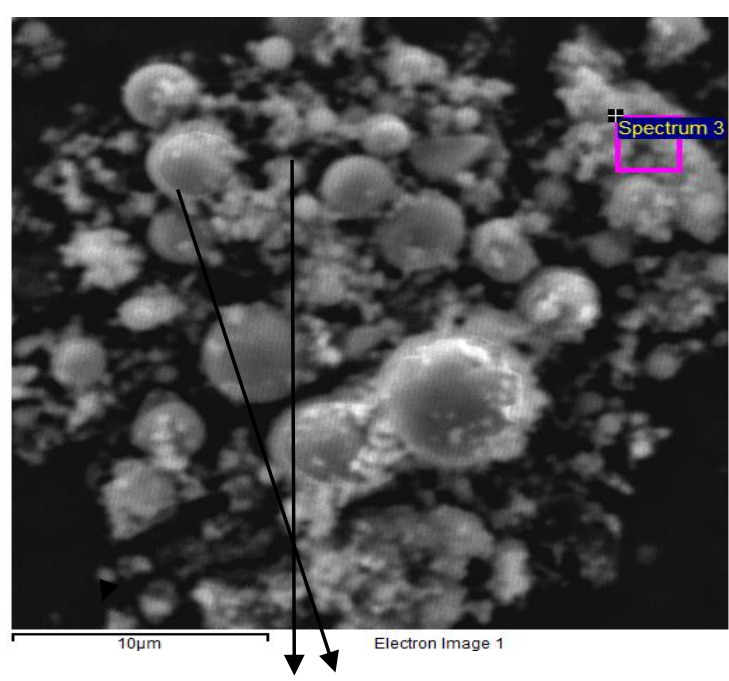

Agglomerated aluminium particles.



\begin{tabular}{|c|c|c|}
\hline Element & Weight \% & Atomic \% \\
\hline $\mathrm{C} \mathrm{K}$ & 19.65 & 28.35 \\
\hline $\mathrm{O} \mathrm{K}$ & 46.09 & 49.93 \\
\hline $\mathrm{Al} \mathrm{K}$ & 32.77 & 21.05 \\
\hline $\mathrm{Si} \mathrm{K}$ & 0.38 & 0.23 \\
\hline $\mathrm{Cl} \mathrm{K}$ & 0.52 & 0.25 \\
\hline Fe K & 0.59 & 0.18 \\
\hline Total & 100.00 & \\
\hline
\end{tabular}

Figure 3. SEM Image and EDS Chemical Spectrum of Ultra-fine Aluminium Sample Quench Collected at 8MPa. 


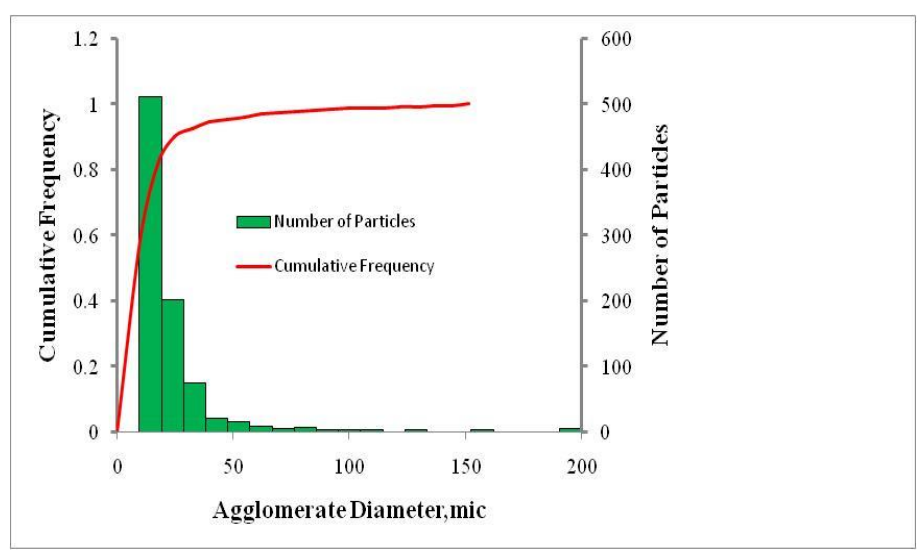

Figure 4. Size Distribution and Cumulative Frequency of AgglomerateDdiameter for Ultra-fine Propellant sample at $2 \mathrm{MPa}$.

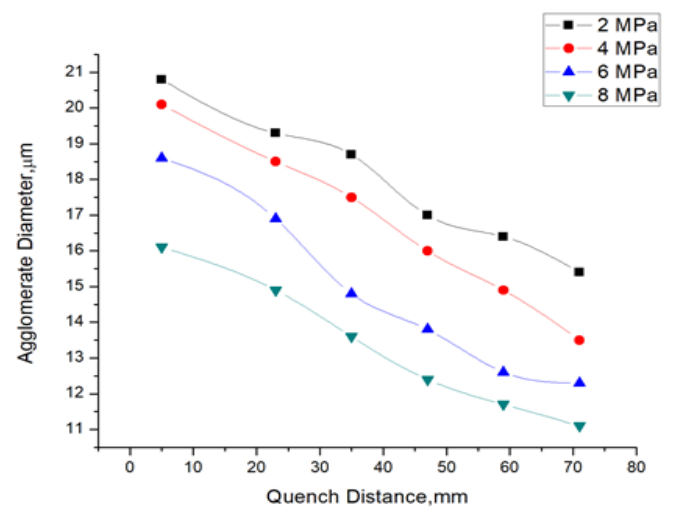

Figure 5. Aluminium Agglomerate Diameter Versus Quench Distance.

Chemical analyses of the friable exudation reveal the presence of metal oxidation products with some intermediate combustion products and residual unburned metal. Exudation is due to ultra-fine aluminium aggregation. Once the aggregation flakes emerged at the burning surface, these can complete combustion crumbling into condensed combustion products particles reminiscent of their original size. Considering the propellant, microstructure pockets between the coarse AP particles contain a matrix of metal, fine AP, and the binder. The initial size of aluminium and the amount of aluminium present in the propellant have a decisive effect on the size distribution of agglomerates leaving the 
propellant surface. In ultra-fine aluminized propellants, the higher number density and high surface energy of aluminium particles lead to higher rate of accumulation and formed larger size agglomerates. The extent of agglomeration is of the order of $11 \mu \mathrm{m}$, i.e., $11000 \mathrm{~nm}$, which itself is about 24 times the original ultra-fine aluminium powder size. As pointed out, several factors control the aluminium agglomeration features, such as parent aluminium size, operating pressure, sizes of coarse and fine AP particles, flame structure, matrix (without coarse AP) fraction and its contents. From the above, two factors are already investigated by authors which can be related to compare the present study with other researchers' outcomes, namely, combustion pressure and parent aluminium particle size. It was noticed that the possibility of aluminium agglomeration and its size is relatively low at high pressure and with large parent aluminium sizes of micro-aluminised propellants (Anand et al, 2013), whereas the same trend is observed for pressure effect of the nano-aluminized propellants (Jayaraman, 2010/2011). In the present study, $450 \mathrm{~nm}$ aluminum particles are used which restricts the agglomeration factor range within 24-46. These factors indicate that number density of agglomerate alumina and its sizes need to be accurately estimated from the propellant combustion in order to damp the pressure oscillations in the rocket motors.

\section{Conclusions}

The quench collection experiments were carried out to study and evaluate the ultra-fine aluminium particles agglomeration features emerging from the propellant surface, quenched at different distances for the pressures of 2, 4, 6, and $8 \mathrm{MPa}$. The SEM analysis shows that the ultra-fine particles are in spherical shape. The aluminum agglomerate size and its component analysis are determined using SEM-EDS analysis. The aluminium agglomerate size decreases with increasing pressure and quench distances. At high pressures, the LEFs approach closer to the burning surface and effectively ignite the accumulated aluminium and reduce its sizes. The possibility of aluminium agglomeration and its size is relatively low at high pressure and with large initial aluminium sizes. The aluminum agglomeration factor is in the range from $24-46$. The largest size of agglomerates with ultra-fine aluminium does not exceed $21 \mu \mathrm{m}$. This factor is likely to be benign for reduced smoke propellant applications from an exhaust signature viewpoint, without significantly sacrificing the energetic of the propellant. The two-phase flow loss to thrust and possibly slag accumulation can be significantly overcome with the smaller sized aluminium agglomerates particles and subsequently its combustion efficiency using ultra-fine aluminium in propellants, when compared to its micron-sized $\mathrm{Al}$ counterpart, forms large sized Al agglomerates. 


\section{References}

Anand, K. V., Roy, A., Mulla, I., Balbudhe, K., Jayaraman, K., \& Chakravarthy, S. R. (2013). Experimental data and model predictions of aluminium agglomeration in ammonium perchlorate-based composite propellants including plateau-burning formulations. Proceedings of the Combustion Institute, 34, 2139-2146.

Argonide. (n.d.). Nano material technologies. Retrieved from http://www.argonide.com

Dokhan, A. (2002). The effect of aluminium particle size on aluminized propellant combustion. (Doctoral dissertation, Georgia Institute of Technology). Retrieved from http://adsabs.harvard.edu/abs/2002PhDT $81 \mathrm{D}$

Galfetti, L., De Luca, L. T., Severini, F., Meda, L., Marra, G., Marchetti, M., .. . Bellucci, S. (2006). Nanoparticles for solid rocket propulsion, Journal of Physics: Condensed Matter, 18, 51991-52005.

Galfetti, L., DeLuca, L. T., Severini, F., Colombo, G., Meda, L., \& Marra, G. (2007). Pre and post-burning analysis of nano-aluminized solid rocket propellants, European Conference for Aerospace Sciences, EUCASS, 11, 26-32. Moscow, Russia.

Gash, A. E., Simpson, R. L., Babushkin, Y., Lyamkin, A. I., Tepper, F., Biryukov, Y., ... Zarko, V. (2005). Nanoparticles. In U. Teipel (Ed.), Energetic Materials: Particle Processing and Characterization, 237. Weinheim, Germany.

Gen, M. Y., \& Miller, A. V. (1981). Method of obtaining metal aerosols, USSR inventors Certificate No. 814432. Bulletin of Invention, 11, 25 [in Russian].

Gen, M. Y., Ziskin, M. S., \& Petrov, Y. I. (1959). Study of size distribution of Al aerosol in dependence of operational conditions, Doklady AN SSSR, 127, 366 [in Russian].

Glotov, O. G. (2006). Condensed combustion products of aluminized propellants IV effect of the nature of nitramines on aluminium agglomeration and combustion efficiency. Combustion, Explosion Shock Waves, 42, 436-449.

Gutmanas, E. Y., Trusov, L. I., \& Gotman, I. (1994). Consolidation, microstructure and mechanical properties of nanocrystalline metal powders. Nanostructured Materials, 4, 893-901.

Haber, J. A., \& Buhro, W. E. (1998). Kinetic instability of nanocrystalline aluminum prepared by chemical synthesis; facile room-temperature grain growth, Journal of the American Chemical Society, 120, 10847-10855.

Jayaraman, K., Anand, K. V., Bhatt, D. S., Chakravarthy, S. R., \& Sarathi, R. (2009b). Production, characterization, and combustion of nano-aluminium in composite solid propellants. Journal of Propulsion Power, 25, 471-481.

Jayaraman, K., Anand, K. V., Bhatt, D. S., Chakravarthy, S. R., \& Sarathi, R. 
(2009a). Effect of nano-aluminum in plateau burning and catalyzed composite solid propellant combustion. Combust \& Flame, 156, 1662 1673.

Jayaraman, K., Chakravarthy, S. R., \& Sarathi, R. (2010). Accumulation of nanoaluminium during combustion of composite solid propellant mixtures. Combustion, Explosion Shock Waves, 46, 21-29.

Jayaraman, K., Chakravarthy, S. R., \& Sarathi, R. (2011). Quench collection of nano-aluminium agglomerates from combustion of sandwiches and propellants. Proceedings of the Combustion Institute, 33, 1941-1947.

Jigatch, A. N., Leipunsky, I. O., Kuskov, M. L., Stoenko, N. I., \& Storozhev, V. B. (2002). A set-up for obtaining and investigation of metal nanoparticles. Pribory Technikaeksperimenta [Experimental techniques and instruments], 6, 122 [in Russian].

Khan, A. S., Farrokh, B., \& Takacs, L. (2008). Effect of grain refinement on mechanical properties of ball-milled bulk aluminum. Material Science Engineering, 489, 77-84.

Mazalov, Y. A., Bogdanova, V. V., Ivashkevich, L. S., Pavlovets, G. Y., \& Chinnov, V. V. (1993). Composition and structure of ultra-dispersed powders on the basis of aluminum. Combustion, Explosion Shock Waves, 29, 19-32.

Povinelli, L. A., \& Rosenstein, R. A. (1964). Aluminum size distributions from high-pressure composite solid-propellant combustion. American Institute of Aeronautics and Astronautics, 2, 1754-1760.

Price, E. W., Sambamurthi, J. K., Sigman, R. K., \& Panyam, R. R. (1986). Combustion of ammonium perchlorate-polymer sandwiches. Combustion \& Flame, 63, 381-413.

Sai Karthick, P., Chandrasekhar, S. B., Chakravarty, D., Srinivas, P. V. V., Chakravdhanulu, V. S. K., \& Rao, T. N. (2018). Propellant grade ultrafine aluminium powder by RF Induction Plasma. Advanced Powder Technology, 29, 804-812.

Salko, A. E. (1995). Certain aspects of development and use of ultra-fine powdered materials, chemical gas dynamics and combustion of energetic materials. International Workshop, Tomsk, Russia, 27-29 June.

Sambamurthi, J. K. (1996). $\mathrm{Al}_{2} \mathrm{O}_{3}$ collection and sizing from solid rocket motor plumes. Journal of Propulsion and Power, 12, 598-604.

Sanchez-Lopez, J. C., Caballero, A., \& Fernandez, A. (1998). Characterization of passivated aluminium nanopowder: An XPS and TEM/EELS study. Journal of the European Ceramic Society, 18, 1195-1200.

Sedoi, V. S., \& Valevich, V. V. (1999). Obtaining of ultra-fine metal powders by the method of exploding wires in the low-pressure nitrogen. Journal of Technical Physics, 25, 81. 
Simonenko, V. N., \& Zarko, V. E. (1999). Comparative studying the combustion behavior of composite propellant containing ultra-fine aluminium. Paper presented at the 30th International Annual Conference of ICT, Karlsruhe, Germany, pp.21-1-21-29.

Srinivas, V., \& Chakravarthy, S. R. (2007). Computer model of aluminum agglomeration on burning surface of composite solid propellant, Journal of Propulsion and Power, 23, 728-736.

Sun, X. K., Cong, H. T., Sun, M., \& Yang, M. C. (1999). The effect of heat treatment on tensile properties of the cold-compacted nanocrystalline Al. Nanostructured Materials, 11, 917-923. 